\title{
A summary on ergonomics research of the night vision vehicle head-up display
}

\author{
Wei Cai ${ }^{1,2, a)}$, Changqing Liu' ${ }^{1, b)}$, Xiaofeng Zhao ${ }^{1,2, c)}$ and Yinpeng Wei ${ }^{1, d)}$ \\ ${ }^{1}$ Xi'an High Tech Istitute, Xi'an 710025, China. \\ 2 Science and Technology on Electro-optic Control Laboratory, Luoyang 471009, China. \\ ${ }^{3}$ School of Telecommunications Engineering, Xidian University,710071, China. \\ a)caiwei_202@163.com \\ b)464078834@qq.com \\ c)xife_zhao@163.com \\ d)254192230@qq.com
}

Keywords: night vision vehicle head-up display; HUD; ergonomics; Human Factors Engineering

\begin{abstract}
The night vision vehicle head-up display is a new type of vehicle night-assisted driving man-machine interaction device. It has obvious advantages in use. But because the device is the main source of visual information for the driver at night. If the design is not appropriate is likely to cause danger. Analyzed the night vision vehicle head-up display’s work characteristics. Proposed a human-computer interaction model. Finally, the key factors and methods of ergonomics design are discussed.
\end{abstract}

\section{INTRODUCTION}

Special vehicles is difficult to fully grasp the traffic information, especially in the complex environment at night driving, due to the body is very long, bulky, turning radius. Special vehicles will encounter night closing lights driving, complex road changes, snow fog low visibility weather and so on. To the special vehicle night driving has brought great security risks and driving risk, a serious threat to personnel and vehicle safety.

Based on the night vision sensor to enhance the reality of the vehicle head-up display(Hereinafter referred to as: night vision vehicle HUD) using collimation imaging. Travel conditions, environment, traffic conditions and other information images can be collimated on the front of the driver in the mirror, and the location coincide with superposition, with a strong sense of reality, information superposition convenient, in line with human physiological and psychological needs. Enhance driver's environment and traffic awareness to improve vehicle safety in complex environments at night [1].

Head Up Display, referred to HUD, has been widely used on the plane. While the vehicle HUD with the airborne HUD in the use of the environment, combat needs and other aspects of the existence of a larger difference. The vehicle HUD because of the late start, resulting in vehicle HUD ergonomics research is relatively small, "Driver-HUD-environment" man-machine system of poor adaptability [2]. The ergonomic study of vehicle HUD, to provide application demonstration and optimization program, is the urgent need to solve the problem.

The vehicle HUD involved in optical engineering, manufacturing technology, computer science, automatic control, physiology, psychology and interactive interface design and many other fields, technical complexity, application background [3]. For the complex environment, low visibility conditions under the special vehicle night driving and driver physiology, psychological needs. The ergonomic study of "Driver-HUD-environment" man-machine system [4], which can provide ideas and reference for the "Driver-HUD-environment" man-machine system adaptability research of vehicle display equipment. 


\section{ANALYSIS OF THE CHARACTERISTICS OF NIGHT VISION VEHICLE HUD}

\section{Head-up Display}

Head-up display is currently widely used in the aircraft flight auxiliary equipment, is the 60's appeared by a variety of electronic components, display components, controllers, high-voltage power supply and other components of the integrated electronic display device. It can be flying parameters, aimed at attack, self-detection and other information to the image, the form of characters, through the optical components projected into the front of the cockpit on the combination of optical / electrical display device. When the pilots observe the cabin scenery through the combination of glass, you can see the characters, images and other information superimposed on the location. And the projection focal length is located in front of the imaging combination glass, so that the pilot almost no need to change the focal length of the eye, you can easily view the flight parameters at any time, the visibility will not be affected by sunlight. In the past, pilots in the air combat, the need to alternately observe the cabin targets and cabin instruments, easy to produce instantaneous visual disruption, which will lead to slow response, operational errors, and may adversely affect fighters, the use of head-up display can overcome this shortcoming [5].

\section{The Night Vision Vehicle Head-up Display}

Now the head-up display system is developing rapidly and has been used in civilian high-end cars. At present, the high-end car loading HUD can display the main information: the current speed, navigation information, driving support information and warning signals, display information is limited.

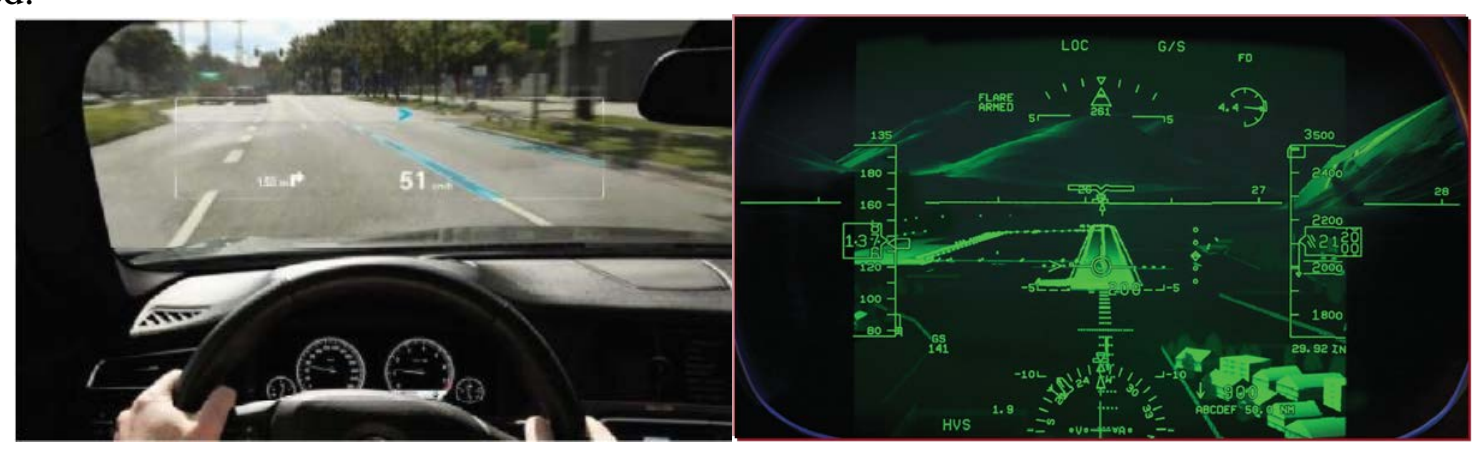

FIGURE 1. Night vision vehicle HUD illustration.

The head-up display is applied to the vehicle in combination with infrared, low light and other sensors, and the vehicle driving information and the location image are collimated on the flat-panel display at "infinity". So that the driver without switching perspective, for the driver to create a real driving environment, can effectively enhance the driver at night and bad weather conditions, the situation perceived ability to improve driving safety. The use of night vision sensor to enhance the reality of the vehicle head-up display is to improve the special vehicle night driving risk, to help the driver to grasp the vehicle information effective measures [6].

HUD in the use of fighter aircraft has been relatively mature, and in the aircraft cockpit carried out ergonomic research has achieved remarkable results, so that the driver can safely, efficiently and comfortably complete the combat mission [7]. However, due to the different application background of the car, the driving demand is obvious. Learn from the successful experience of aviation efficiency, analysis of vehicle head-up display in the human and equipment, people and the environment and the interaction between equipment and the environment. So that the specific people - machine - the flexibility of the system to achieve the best, the driver can safely, efficient and comfortable to complete the night driving.

\section{Research On HUD Ergonomics At Home And Abroad}

The ergonomic study of head-up displays mainly includes the matching of display systems and display media (display devices) with human visual characteristics. China, the United States, Britain, France and other countries on the visual display of visual effects and its influencing factors were a 
lot of research [8], Mainly focused on the shape and size of digital symbols, picture format, display the type and number of information, display information partition and so on.

The use of ergonomics for head-up display design is earlier in the United States and Japan, and is now in a leading position. In particular, the United States has done a lot of man-machine efficiency evaluation of head-up displays in order to improve the efficiency and quality of aircraft manmachine interaction. In addition, the use of head-up display in the process of attention to the distribution, memory load and visual fatigue and other phenomena [9].

China's ergonomic research carried out later, ergonomics in many colleges and universities have just been established. China's aircraft head-up display design is mainly from the results of the former Soviet Union. Due to the lack of man-machine design of the former Soviet Union, so in the early part of China's consideration is also relatively lacking. After the reform and opening up, China's head-up display design began to study in the United States and other developed countries, into the ergonomic design part.

\section{The Night Vision Vehicle Head-up Display Ergonomic Design Reference Principles}

(1) the observation of the comfort, refers to the man-machine interface presented to the user's information color, character font and font size, brightness, contrast and other requirements in line with the degree of human eye.

(2) the comfort of space layout, refers to the man-machine interaction of the work space and environmental conditions in line with the needs of users.

(3) the comfort of the workload, refers to the man-machine interface attached to the control of the visual observation, vision, psychological and other aspects of the load so that the provisions of the control time does not produce uncomfortable, and the degree of completion of the required tasks [10].

(4) the comfort of psychological cognition, refers to the human-computer interface to the user to observe the information display rules, requiring the user's operating procedures in line with the degree of human psychological cognitive characteristics.

\section{THE NIGHT VISION VEHICLE HUD HUMAN-MACHINE INTERACTION MODEL}

Research night vision vehicle HUD man-machine efficiency, is to make the "driver-HUDenvironment" man-machine system to establish the most reasonable combination of internal relations. During the night driving process, the driver's visual response to external information is basically derived from the night vision vehicle HUD[11]. Usually need to go through the perception of memory, decision-making and action execution steps, these sections form a "driver-HUDenvironment" information processing system. The mathematician Wickens has established an information interaction model based on this process. On the basis of the Wickens model [12], established human-machine interaction model based on the night vision vehicle HUD, as shown in Fig.2.

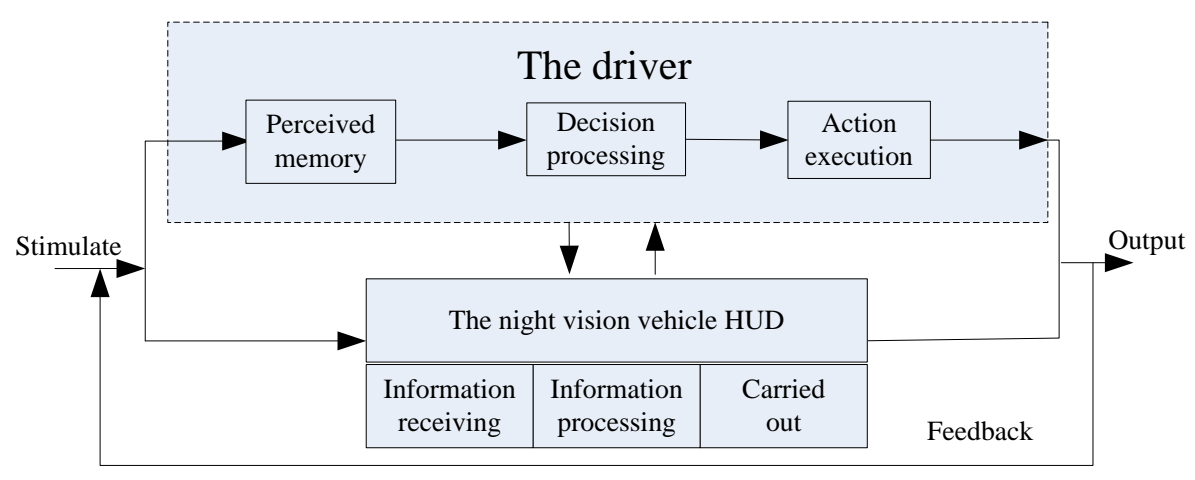

FIGURE 2. Night vision vehicle HUD man-machine interactive model.

The night vision vehicle HUD from design research and development to engineering applications, ergonomic research occupies a very important position [13]. The night vision vehicle HUD communicates the front road information to the driver, makes the correct judgment, and operates 
safely and safely. In night vision vehicle HUD design applications, in addition to accurately reflect the outside world and data status, but also need to be based on the human sensory characteristics to determine its structure and display performance, so that the design and display in line with the driver's driving characteristics, to ensure the comfort and safety of night driving [14].

\section{KEY FACTORS OF THE NIGHT VISION VEHICLE HUD ERGONOMICS DESIGN}

In the ergonomic analysis of head-up displays, need to consider the optical / visual perception, character and other auxiliary information display, the driver physiological factors, the window shows the characteristics of characterization, compatibility with the cockpit environment and many other aspects. The influence mechanism of each factor on ergonomics is analyzed by theoretical analysis and experiment.

\section{Optical / visual perception}

(1) Field of view and eye distance

The field of view of the human visual system is roughly elliptical, the horizontal direction of more than $200^{\circ}$, the vertical direction of more than $130^{\circ}$, the middle of about $120^{\circ}$ area for the binocular overlap area. In the use of large field of view is very critical, while the optical eye is the closest to the eyes of the optical components to the distance between the eyes. The eye is also a very important parameter to be considered in the design of the night vision vehicle HUD [15].

(2) Brightness and contrast

In the ambient light conditions facing the location, the brightness of the head-up display must make the image has good visibility. The brightness of the image depends on the brightness of the image source, the efficiency of the optical system, and the characteristics of the combined glass. The contrast of the vehicle HUD is the ratio of the actual display brightness to the brightness of the exterior, it is also defined as the difference in brightness between two adjacent regions. The image information is mainly transmitted by the contrast that can be patterned. Studies have shown that the use of a variety of new technologies can help reduce the psychological load of the driver using the usual display [16]. The brightness auto-adjustment technique reduces the number of times the driver manually adjusts the brightness and improves the readability of the symbols.

\section{Characters and other auxiliary information}

Character display is the most intuitive form of vehicle working state information, but also constitute an important part of the flat screen display, its design is reasonable or not directly related to the driver's interpretation and operation. Head-up display character brightness, line width is to determine the performance of the important parameters of the pros and cons. Good character display characteristics determine the flat in the high-intensity external light or dark night and other environments under the visibility of the characters and observe the degree of comfort.

Head-up displays can display a wide variety of information, including: speed, oil temperature, air pressure, alarm, maps and so on. The more symbols on the screen, will lead to the more crowded the screen. Inappropriate picture and symbol design will have a negative impact on the driver's night driving. It is necessary to reduce the negative impact of adding unnecessary symbols as much as possible, and whether the evaluation of the symbol system is appropriate, that is, the evaluation of the performance of the symbol system in practical application [17]. Therefore, the effective method of evaluation is to integrate the symbols into the comprehensive task, analyze the symbols in reducing the psychological load, improve the situation to understand the effectiveness of the situation.

\section{Driver Physiological Factors}

(1) Attention distribution

In the process of using the car flat, due to the needs of the task, or because of the driver's attention to the distribution of errors, attention focused on the narrower central visual range, the information presented at the edge of the screen or the unexpected events outside the cab did not 
cause the driver's attention, causing the driver to miss some critical information, known as the cognitive pipeline effect. For example, if the auxiliary display vehicle and equipment information symbols are too attractive to the driver, so that their attention over the symbol, the response time of the incident significantly extended.

(2) Psychological load

The psychological load of the driver of the special heavy vehicle reflects the psychological workload in the process of driving the vehicle, which is manifested in the sense of perception, thinking, decision making and so on. Psychological load by a variety of factors, such as weather, traffic, display information to understand the difficulty and so on. When the driver drives the vehicle at night, his psychological load is often at a high level.

The brightness automatic adjustment technique improves the readability of the symbols. Synthetic display, three-dimensional display and large field of view technology can reduce the number of driver head rotation, increase the display screen and cabin similarity. The color display technology utilizes the parallel processing characteristics of color to speed up the extraction of color symbols. These techniques can make the flat signs easy to perceive, easy to search, easy to understand, to reduce the driver to read the screen to pay the psychological work [18].

(3) Physiological load

The use of night vision vehicle HUD on human vision, the brain generated by the workload is within the expected range. Straightening fit and adaptation problems Because of the differences in body size and physiology of different sexes, the position, size and comfort of the driver must be taken into account.

\section{HUD window display format}

(1) Display information layout

Head-up display not only for heavy-duty vehicle drivers at night driving to provide infrared and low light night vision after the integration of traffic enhancement images, but also to provide some of the vehicle state information. And how the various types of information on the monitor intuitive and accurate display, in line with the driver's operating habits, easy to quickly reflect the driver, can not do without a reasonable display information layout. Display information layout unreasonable will directly cause the driver's visual fatigue, affecting work efficiency, and even cause accidents. Therefore, head-up display display information should be fully considered ergonomic requirements, as far as possible to meet the driver's habits.

(2) Basic display format and main screen display format

Head-up display display format is the key to information display, in full consideration of the information on the basis of partition, determine the basic display format in different states, display the shape and size of the digital symbols in the format, the types of information, the number of information, and so on. And should be combined with the information density, visual scan time and information search time to determine the various main screen display format of the various requirements [19].

\section{Compatibility of night driving environment}

During nighttime driving, the character brightness of the night vision vehicle HUD should be compatible with the overall illumination environment of the cab, allowing the driver to quickly and accurately identify the various colors of the characters presented on each picture, but also to maintain a good visual dark adaptation, and thus smoothly inside and outside the cab alternately observed.

Therefore, the appropriate brightness and brightness limits of the flattened characters during nighttime travel should be determined by experiment. Among them, the appropriate brightness of the characters is to ensure that the minimum color of the various characters are clear and easy to distinguish, and more comfortable in the visual.The upper limit of the brightness of the character is the maximum brightness that does not affect the dark adaptation of the nighttime observation of the cabin, in order to improve the visual effect of the display, to ensure safe driving [20]. 


\section{CONCLUSION}

There are many aspects of the ergonomic design of the night vision vehicle HUD that need to be considered. Such as: dynamic performance problems; matching with the same, listening and speaking functions; strong light interference problems; HUD and various types of display instrument compatibility issues and so on. With the deepening of people's understanding of these issues, designers are required to change their minds, from the previous product functional performance indicators as the center, to a people-centered consideration. In the future, we should actively focus on the key technologies of the night vision vehicle HUD ergonomics, to carry out the relevant special test and test validation, improve the "driver - head-up display - environment" manmachine system Adaptability.

\section{ACKNOWLEDGMENTS}

This work was financially supported by Science and Technology on Electro-optic Control Laboratory and Aeronautical Science Fund (No.201551U8008).

Corresponding Author: Changqing Liu, master's degree, 464078834@qq.com, 18591955817.

\section{REFERENCES}

[1].REN Jin-dong, CHEN Jing-hui, LU Shan-bin, etc. A Research on the Use of Anthropometric Data in Vehicle Ergonomic Design[J]. Automotive Engineering, 2013, 35(6):505-509.

[2].Yeh C K, Fang Y P, Shih K Y, et al. Ergonomic Analysis of the Automotive Head-Up Displayed Information[C]. Advanced Engineering Forum. 2013:327-330.

[3].CAI Qi-ming, YU Zhen, ZHUANG Chang-yuan. Human Factors Engineering[M]. Science Press, 2011:8-16.

[4].LONG Sheng-zhao. Theory and Application Foundation of Human - Machine - Environment System Engineering[M]. Science Press, 2004:12-19.

[5].Melzer J E, Brozoski F T, Letowski T R, et al. Guidelines for HMD design[J].Helmet-Mounted Displays: Sensation, Perception and Cognition Issues,2009:805-848.

[6].Kurita K. Non-contact and non-attached human hand motion sensing technique for application to the human machine interface IEEE, 2010:3536-3539.

[7].Liu X, Wang L, Li X, et al. Comparative study on flight reference symbology for helmetmounted display based on eye tracking technology[C]//Industrial Informatics (INDIN), 2012 10th IEEE International Conference on. IEEE, 2012:459-463.

[8].Hsieh S, Rash C E, Harding $\mathrm{T} \mathrm{H}$, et al. Helmet-mounted display image quality evaluation system[J]. Instrumentation and Measurement, IEEE Transactions on,2003,52(6):1838-1845.

[9].Rash C E. A 25-year retrospective review of visual complaints and illusions associated with a monocular helmet-mounted display[J]. Displays,2008,29(2):70-80.

[10]. Reyes M L, Lee J D, Liang Y, et al. Capturing driver response to in-vehicle human-machine interface technologies using facial thermography[C]/Proceedings of the International Driving Symposium on Human Factors in Driver Assessment, Training and Vehicle Design. University of Iowa Public Policy Center, 2009, 5:536-542.

[11]. REN Jin-dong, FAN Zi-jie, HUANG Jin-ling. An Overview on Digital Human Model Technique and Its Application to Ergonomic Design of Vehicles[J]. Automotive Engineering, 2006, 28(7):647-651.

[12]. Tanuma K, Sato T, Nomura $M$, et al. Comfortable design of task-related information displayed using optical see-through head-mounted display[C]//Human Interface and the Management of Information. Interacting with Information.Springer, 2011:419-429. 
[13]. WANG Yong-sheng, LIU Hong-man. A summary on Human/System Performance of Airborne HMSDS[J]. Electronics Optics \& Control, 2014(7):1-5.

[14]. ZHANG Jian, WU Chao. Study on Principles of Safety Ergonomic System from a Theoretical Perspective[J]. China Safety Science Journal, 2013, 23(6):14-19.

[15]. WU Chao, YANG Mian. Study of safety science principles and their constructions[J]. China Safety Science Journal, 2012, 22(11):1-8.

[16]. HAVIG P R. Luminance contrast and color recognition in Helmet- MountedDisplays[C]//Proceeding of SPIE, Helmet-and head-mounted displays VI. Orlando:USA, 2001: 198-204.

[17]. FU Y Q, XUB H. Review of principles and evaluation methodologies for cockpit helmetmounted displays symbology[J]. Space Medicine \& Medical Engineering 2013, 26 (5) :415419.

[18]. WU Y W, QIAO Z L, LI B Y, et al. Pychological health inventory for military pilots[J]. Chinese Journal of Convalescent Medicine, 2008, 17(11) : 696-698.

[19]. Brandstaetter J, Yatsiv I, Kadosh I, et al. Eyeball: An inertial helmet mounted cueing system IEEE, 2008:217-224.

[20]. WANG Li-wei, WANG Jian-zhen. Development of HUDs on military aircraft in advanced countries[J]. Infrared and Laser Engineering, 2007, 36(s2):578-582. 